\title{
Investigation and Research on Opera of Poyang Lake Area in Northern Jiangxi
}

\author{
Shilai Ouyang \\ Art Institute \\ Jiujiang University \\ Jiujiang, China 332005
}

\begin{abstract}
This survey is based on the counties of Jiujiang City in the Poyang Lake area of northern Jiangxi. The survey objects are mainly the national intangible cultural heritage (Qingyang opera and Xihe opera) and the provincial intangible cultural heritage (Nanhe opera, Tea-picking opera, Ninghe opera, and Yaya opera).
\end{abstract}

Keywords-Poyang Lake area; opera; intangible cultural heritage

\section{INTRODUCTION}

Folk art is a living culture that evolves as society develops. Folk opera is one of the important contents of the protection of intangible culture and one of the important means of cultural exchanges between regions. The Poyang Lake area in northern Jiangxi has a long history and is rich local cultural resources, with its own unique cultural customs and various folk opera dramas. From 2007 to 2010, Jiujiang Cultural Department organized experts and scholars to investigate the folk operas in the region. In order to clearly understand the changes in the opera of this region in recent years, and its current state, this project conducted a special investigation of the above-mentioned operas in the Poyang Lake area of northern Jiangxi by using the method of combining key point and universality to provide first-hand reference materials for the protection of intangible cultural heritage in the region through literature review and field survey.

\section{THE PURPOSE AND SIGNIFICANCE OF THE OPERA} INVESTIGATION IN THE POYANG LAKE AREA IN NORTHERN JIANGXI

The investigation work was carried out under the current environment of intangible cultural protection and research policies in China, mainly targeting Qingyang opera, Ninghe opera, Raohe opera, Xihe opera, Nanhe opera, Wuning tea picking opera, Ruichang tea picking opera and Jiujiang tea picking opeara in the Poyang Lake area of northern Jiangxi. The survey sites include Jiujiang City, Ruichang City, Hukou County, Xingzi County, Duchang County and Pengze County. Due to the constraints of various objective factors, this investigation can only adopt the method of acting according to circumstances, combine with the implementation of the protection of intangible cultural heritage, and conduct investigations from point to surface by using typical surveys, sample surveys, statistical surveys and other methods. The typical investigation takes the most influential opera and representative troupes of the opera as the object, which has certain representativeness. The sampling survey adopts randomness, which is conducting investigation on the performance of a folk theater group in a certain village in the slack season, wedding and funeral ceremony, and around the Spring Festival, to ensure the authenticity and accuracy of the survey data. The random survey can truly understand the performance customs of the folk troupe, understand its cultural connotation on this basis, and see the relationship between the opera and the audience in the performance. The statistical survey is based on data provided by local cultural departments.

\section{THE HUMANISTIC BACKGROUND OF THE OPERA IN POYANG LAKE IN NORTHERN JIANGXI}

Folk custom is a kind of life culture created and passed down by the people, which covers all aspects of people's lives and is an important manifestation of people's lives. The Poyang Lake area in northern Jiangxi has a long history. People have lived in this particular living environment for a long time, and carried out various production practices in this environment. In a series of social activities, they have formed the folk customs with the characteristics of the Poyang Lake region, including production, life, religion and rituals. Especially the traditional opera culture that has spread here formed a unique local cultural custom.

In the Poyang Lake area of northern Jiangxi, there are many kinds of operas, such as the Tanxi opera, Wenqu opera, Raohe opera, tea-picking opera, puppet show, shadow puppetry, and so on and more than 110 village-level peasant troupe, so it is called "the hometown of Jiangxi opera." According to experts' research, the earliest opera in the Poyang Lake area in northern Jiangxi emerged in the Ming Dynasty, which is mainly based on historical records. For example, Tang Xianzu's "Record on the Shenqingyuanshi Temple in Yihuang County" records that the Qingyang opera was spread to Jiangxi during the Jiajing period of Ming Dynasty after its formation and prevailed in Jiujiang area. In the first year of Wanli (1573), Qiangyang opera appeared in in Linchuan, the hometown of Tang Xianzu. According to "Records of Duchang County", "Qingyang opera was introduced to Duchang in the thirty-eight years of Wanli 
period in Ming Dynasty (1610). Its songs were written by the literati and people in the county are keen on copying it, making every household collect it. Especially In the countryside, people can learning operas and become literate through, so it has been prevalent in Duchang for 300 years. The long-established opera culture in northern Jiangxi can also be illustrated by the stage. In the Qing Dynasty, in the ancestral hall of Liu family in Dadeshan and that of Hong family in Dawu located more than 100 kilometers away from Ruichang County, can be found the brick-wood structure, a performance venue for the performance of opera class and the wing-room for the East and West field of band. The folk stage also shows that opera activities have been popular in folk. After the founding of New China, the construction of opera culture was valued, and various opera training classes were held under the support of government departments. Excellent repertoire and opera actors continued to emerge. During the Cultural Revolution, the folk operas in northern Jiangxi were rebuilt as in the rest of China, and folk opera activities were almost stagnant. Nowadays, some folk opera troupes have also shrunk greatly, and some operas are even on the verge of extinction. In this survey, individual operas such as shadow puppetry and Peking Opera were not included in the survey objects.

\section{THE CURRENT SITUATION AND ANALYSIS OF THE OPERA IN POYANG LAKE AREA IN NORTHERN JIANGXI}

\section{A. The Opera and Existing State of Folk Operas in the Poyang Lake Area of Northern Jiangxi}

1) The kinds of operas: There are nine kinds of representative operas in the Poyang Lake area in northern Jiangxi in current survey mainly distributed in different counties and cities, including Qingyang opera, Ninghe opera, Raohe opera, Xihe tanqiang, Nanhe opera, Wuning Teapicking opera, Ruichang tea-picking opera, Jiujiang teapicking opera, and Xihe opera. These operas have more or less performances.

2) Performance groups: There are three types of operas in northern Jiangxi, including professional performance groups, semi-professional performance groups, and nonprofessional performance groups.

3) The basic composition of the audience: The audience can be roughly divided into urban audience group and township rural audience group. Some large local dramas such as Qingyang opera have two major categories of audiences, which have a certain audience in cities, towns and villages. At present, all kinds of operas in the northern Jiangxi Opera mainly take the township audience as performance objects.

4) Management of the cultural department: The Mass Art Museum and the Cultural Center will conduct the management method of professional guidance for semiprofessional troupes and non-professional troupes by sending personnel to conduct professional guidance for rural and school amateur troupes, to improve the artistic level of performances, and invigorate the cultural life of the masses when playing the role of making cultural market management in order.

\section{B. Analysis of the Current Situation of Folk Operas in} Poyang Lake Area in Northern Jiangxi

1) Overview of the current situation of various kinds of operas: The operas in the Poyang Lake area in northern Jiangxi are mainly distributed in different cities and counties. The opera cultures of each region intersect with each other and extend to each other, among which the most influential one is Qingyang opera, and other operas are basically influenced by the opera.

Since Qingyang opera was introduced into Jiangxi from Anhui in the Ming Dynasty, the northern Jiangxi has become its main activity area, and it has almost passed through various areas of Poyang Lake in northern Jiangxi, taking dominant position in this area. Because Qingyang opera is a large-scale opera in this region, the classes, repertoires and entertainers have more historical deposits, which embody the long and heavy opera culture in the region. In this area, there is a certain scale of audience in Qingyang opera, most of which are mainly concentrated in rural areas. In some towns, the performances of non-professional groups of Qingyang opera are more frequent, but there is also a tendency toward shrinking. Ninghe Opera, Raohe Opera, Xihe Tanqiang, Nanhe Opera, and Xihe Opera still retain some vitality, but they are gradually shrinking, and some basically return to the form of folk sacrifices. Tea-picking operas in various regions are still having some activities in the village. The current status of other small-scale operas is not optimistic.

The above-mentioned various operas in the Poyang Lake area of northern Jiangxi had a short recovery period and development period in the $1980 \mathrm{~s}$, and then began to show a gradual decline trend, and some operas even faced a crisis of disappearance.

2) Analysis of the audience: The audience of the above various operas can be roughly analyzed according to the distribution of villages, towns and cities. Among them, the rural audience is the largest group of audiences. The concentrated villages, single economic situation, intensive social relationship, and traditional moral concept make the audience have a large demand for traditional operas, but the constraints of conditions of performance troupes at various level have reduced the performance ability of the traditional operas, which is far from satisfying the demand, resulting in the disconnection between the performance groups and the needs of the rural audience. At the same time, this is also the reason why the professional performance groups have difficulty in surviving. Most of the non-professional performance groups are spontaneously organized by the rural people, and the operas are mainly taught by folk old artists who retain the traditional dramas. The traditional excellent repertoire is highly integrated with traditional Chinese ethics and morality, and it is very easy to be accepted and recognized by the people. Therefore, these village spontaneous performance groups have a large 
audience, and they have become the main communicators of traditional opera and traditional culture. Previously, a large number of rural young adults basically chose to go out to work, so we are also faced with the problem of how to cultivate the audience.

The urban audience group is the main carrier of urban culture in China. Urban culture is a very diverse culture, with a variety of cultural consumption modes. However, there are not many people who choose traditional opera as cultural consumption and their need for opera is not big. Although, under the care of various policies, with the help of some people who love drama, some professional performance groups made efforts for years, the urban audience of the opera has not been expanded, and furthermore, there is the phenomenon of shrinking. Compared with the single lifestyle of the rural audience, the urban audience has a variety of lifestyles, so less people choose to consume opera culture. Due to the higher fares for the opera, people are not willing to spend a lot of money on it, and if the fare is lower, it will be difficult for the troupe to maintain their own survival because of the high the cost of opera. Compared with the traditional repertoire, the demand for modern creative drama is bigger, and the modern creative repertoire generally requires higher stage visual effect, which further increases the input cost of the troupe.

The township audience is between the rural audience and the urban audience. As far as the current situation in the Poyang Lake area in northern Jiangxi is concerned, the aesthetic taste of this group has gradually transform to that of the urban audience, but they can still accepts traditional opera. With the continuous development of the economy, the continuous diversity of cultures and the diverse forms of cultural consumption, the acceptance of traditional operas by these audiences will also decrease.

\section{3) Investigation and analysis of typical opera:}

a) Qingyang opera (taking the troupe as an example): Qingyang opera is one of the folk operas in the Poyang Lake area of northern Jiangxi as well as the most influential opera in the region. It is mainly popular in Jiujiang City, Hukou County, Duchang County, Xingzi County, Ruichang County and Pengze County. As one of the most influential operas in the region, it is one of the key objects of our investigation. Qingyang opera was formed in Anhui, and developed very rapidly after being introduced into Jiujiang area in the Ming Dynasty. There are many professional troupes, and every village has the performers. The Qingyang gongs and drums almost resound on the shore of the Poyang Lake. Until 1940s, there are professional troupes' activities.

Qingyang opera has troupes in Hukou, Duchang, Ruichang and Xingzi. Among them, the Hukou troupes mainly include:

Xiulan troupe was built in the fourth year of Daoguang (1824), with the leader Xia Yankui, at Xiajia ban of Fulong village. The main repertoire include: "Pipaxing", "Qingmeihui", etc. The main actors are Ge Lingzu, Zhou Naosheng, and Xia Yankui.
The old Xiulan troupe gained the name because it is composed of older artists with deeper artistic attainments. It was built in the third year of Tongzhi (1864), at Liuyisi Village of Raotang, Wenqiao town with the leader Liu Hengzhen. The main performances include "Mulian Rescuing the Mother", "Zhengdong" and "Zhengxi". The old Xiulan troupe has a neat lineup and strong strength, with a group of actors who have deep artistic abilities and are very popular with the masses, such as Xu Demao and Xu Qingbao.

Fuxiulan troupe, named after the "Fu" character of leader Wu Xiefu, was built in the 30th year of Guangxu in Qing Dynasty (1904) at Wushangban, Zhangqing Township. The repertoire of the troupe is mainly Yue Fei opera. The main actors are $\mathrm{Wu} \mathrm{Xieshou,} \mathrm{Xu}$ Huashou and so on.

Zhongxiulan troupe, of which the predecessor was a seated singing class, was built in the 30th year of Guangxu (1904) at Liaoba lane, Liusi Township.

The new Xiulan troupe is named so because backbones of the troupe are the young people. It was built in 1944, located in Luoyi Village, Dalong Township. The troupe mainly performs the Opera about the Three Kingdoms.

Qingyang Opera Troupe of Fuyang Township is the only private group that is publicly assisted in the name of the township in China. The group is composed of counselor Yin Wuhuan, a national-level successor, provincial-level successor Zhou Lunrong and a group of young Qingyang opera fans of Fulong Township. In June 2008, Yin Wuhuan founded the "Wu Huan Qingyang opera Training Institute" in his own name, recruiting 36 members for free to participate in the performance with the group. Since its establishment, the troupe has performed special lectures for the China Jiujiang Qingyang Opera Symposium, CCTV "Opera Collection", and the Ministry of Culture's intangible cultural heritage, received universities, experts, scholars and researchers from all over China and performed for them. It was also invited to carry out face-to-face demonstration for the teachers and students in the campus.

At present, the form of inheritance in this region is mainly the master leading disciples, the youngest among which in his forties. In addition, the Hukou Qingyang opera, which is dominated by the Hukou County Cultural Center, perform regularly in the county theater; when holding the weddings and funerals in various places, the Cultural Center sends people to teach singing in the villages, usually with their own instruments - erhu, suona and so on. In addition, according to the arrangement of the county cultural center, they often perform for the secondary schools.

In addition, there are also some professional troupes in the history of Xingzi, Ruichang and Duchang, which have basically disappeared. In recent years, professional troupes have disappeared, and amateur troupes have gradually shrunk. The repertoires are mainly based on traditional repertoires, and traditional forms of performance are mostly retained in form. There are many reasons for this shrinkage.

There are many reasons for the above. First is the desertification of talents. Some outstanding talents have left directly while some personnel trained by the art academy are 
not willing to devote themselves to this. The talents are in a state of temporary shortage, and the quality of the performance is gradually declining. Second is the desertification of the audience. A large number of viewers are losing, because most of the young people are unwilling to watch opera, and the audience of professional opera troupes has also dropped sharply. Nowadays, the troupes rarely sell tickets in the city because the audience group is too small. Selling tickets in the town will result in loss today. Third is the diversification of cultural consumption. With the development of the economy, the rural economic model of villages in the town has also undergone great changes. It has broken away from the simple farming economy, and the way of life also changes with it. Besides, the development of economy and technology enables urban culture to influence rural culture, so the cultural consumption of the masses also becomes diversified.

b) Xihe opera: Xihe opera is commonly known as the full-scale opera, Xingzi opera, and its scientific name is Tanqiang. There have been many sayings about the title of Tanqiang. Some people think that it is "Qingyang Princess Xingyi Yihe Troupe" created by Qingtang Dayue and the disciple after introducing it to Xingzi. It is only accompanied by the erhu and Yueqin. Because the Yueqin is a plucked instrument, it is called Tanqiang; another version is that when the Kun Opera was popular in the Ming and Qing Dynasties, other operas were degraded as shit song and named Luantan, and Tanqiang was named after it. The official name of Xihe Opera was gotten in 1979, which was symmetrical with Donghe West of Ruijin County. It was officially renamed in 1982.

The main troupe of Xihe Opera was Xingzi Yihe Class, which was officially established in 1874 and dissolved in 1950. In the long-term artistic practice, a complete set of rules and performance procedures have been formed. The mainly included previous periods are shown in "Table I"

TABLE I. The Main Troupe of Xihe Opera ANd Previous PERIODS

\begin{tabular}{|l|l|}
\hline \multicolumn{1}{|c|}{ All previous leader } & All previous time \\
\hline Period of leader Zhou Zixiu & $1874-1887$ \\
\hline period of leader Liu Dunhou & $1888-1900$ \\
\hline period of leader Zhou Zhaosheng & $1901-1910$ \\
\hline $\begin{array}{l}\text { Period of southern troupe leader } \\
\text { Zhou Zhaosheng }\end{array}$ & $1910-1923$ \\
\hline $\begin{array}{l}\text { Period of northern troupe leader } \\
\text { Tang Zaishu }\end{array}$ & $1910-1923$ \\
\hline Period of leader Wan Zhengbang & $1924-1930$ \\
\hline Period of leader Huang Jijin & $1930-1935$ \\
\hline Period of leader Guo Zhangyi & $1936-1945$ \\
\hline Period of leader Huang Jijin & $1945-1950$ \\
\hline
\end{tabular}

After the dissolution of the Yihe class, artists established "Operatic Circle Club" in order to facilitate the communication, and the members of Yihe troupe and Tanqiang artists in various regions are members of it. Every year, on the "Yue Wang" birthday (August 28th of the lunar calendar), members of the Operatic Circle Club will sing together for three days to commemorate.
Nowadays, the inheritance form of Xingzi Xihe Opera is mainly the form of the master leading apprentice. There is no professional troupe, but some folk non-professional groups in the towns and villages. The members of these nonprofessional groups spontaneously organized a live performance when there is weddings and funerals. Under the great situation of new rural construction, the villages are building the Family Ancestral Hall, which has become the stage for Xihe Opera performances for various festivals in the country. In addition, the government departments are also more concerned about the protection and inheritance of Xihe Opera. The county cultural department regularly holds the theater performances of Xihe Opera every year. At the time of the performance, even some audiences actively perform on the stage to exchange with each other.

In the absence of a professional troupe, the folk spontaneous troupe organization represents the cultural beliefs of the people. Xihe Opera currently has vast audience in the countryside, but the industrialized production mode dominated by the market economy has caused a large number of rural young adults to flood into the city, resulting in the loss of some most important audience. The performances of folk non-professional troupes are also basically entertainment, lacking artistry.

4) Existing repertoire: The traditional opera highlights performed by the folk troupe recorded in Qingyang opera include "Pan Ge missing his wife", "Guifei drunkenness", "Grinding axe at night", "Three Wars with Lv Bu", "waiting for chasing boats at night", "Hunting back the book", "Meeting in the mills", "Fu Rong press for debts" and so on. The traditional script (including the opera highlights with music score, the lyrics, and spoken parts, and that with music score and the lyrics without spoken parts) include thirty-nine scripts "Hundred Flowers presenting the Sword", "Fighting in Changsha", "Fengyi Pavilion", "Sifan" and "The Story of Pipa", "Qingmeihui", "Record of Colorful Mansion", "Looking for the Family", and "White Rabbit"; the created modern repertoire are less, mainly including "Swallow Coming Back" that describe college students returning to their hometowns and some small operas for the occasion.

\section{INHERITANCE AND DEVELOPMENT \\ COUNTERMEASURES OF OPERA IN POYANG LAKE AREA IN NORTHERN JIANGXI}

\section{A. Conducting Deep Census Work on Operas in the Poyang Lake Area in Northern Jiangxi}

Through deep census work, it is possible to fully understand and master the types, quantity, distribution, living environment, protection status and existing problems of the opera resources in the region, find out the historic evolution of the emergence and development of opera in the region and the basic situation of artist inheritance, and extensively collect the traditional repertoire, script, vocal music, performing arts, related equipment and other materials to make up for the lack of previous work and related information lost due to historical reasons, and carry out 
classification and sorting. We organized and compiled the "History of the Opera Art in the Poyang Lake Area in northern Jiangxi" and the "Dictionary of Opera in the Poyang Lake Area in northern Jiangxi" to discuss the protection, inheritance, reform and development of the opera in the new situation in the region combining with academy in form of summary. It is necessary to make full use of modern hightech means to protect the opera in the region. Video and digital multimedia means are used to collect and organize audio and video materials.

\section{B. Adhering to the Leading Role of the Government, and Government Leadership, Attention and Support Are Keys}

The whole process of discovering and inheriting the operas in the Poyang Lake area in northern Jiangxi has always been carried out under the guidance of the party's "double-hundred guidelines". The attention of the provinciallevel cultural departments has played a decisive role. The development and the discovery of Qingyang Opera art show that the independent support of the county-level government departments has difficulty in finance and manpower. It must be coordinated by the provincial departments and given various forms of help and support.

\section{Paying Attention to the Role of Experts and Further Expanding the Research Team of the Opera History}

Today, some opera arts are discovered in the remote places by experts who have made great achievements in the study of opera art. In addition to attaching importance to and playing the role of the older generation of experts, we should also train and build a new group of young backbones so that they can possess professional knowledge in the history of opera and have the ability to record, organize and innovate in traditional heritage, which is one of the keys to the renewal of ancient tune.

\section{Overall Protecting Opera and Its Activity Space in Poyang Lake Area in Northern Jiangxi}

It is suggested to pay attention to the relationship between the opera and the national cultural ecological environment in the region, implement flexible and effective policies and measures, and foster an environment conducive to the preservation, protection and development of opera. The festival activity is a cultural time and space of the inheritance of opera, so we should continue to support the holding of the opera art festival, so that it can be passed down and developed in the cultural environment.

\section{E. Adhering to the "Marriage" Between Local Governments and Universities, and Working Together to Protect and Inherit the Opera Culture}

Colleges and universities are the carrier of education as well as the promoter of cultural inheritance and innovation. The local opera management department is the bridge and link between colleges and local culture. Universities and local government can carry out cooperation of intangible cultural heritage projects, establish intangible cultural heritage practice bases, set up intangible cultural heritage disciplines, guide intangible cultural heritage scientific research, organize intangible cultural heritage academic exchanges, and carry out campus activities of intangible cultural heritage theme, etc., which are effective content and methods for universities and localities to work together to protect and inherit opera culture.

\section{CONCLUSION}

Vigorously promoting cultural innovation is the guiding direction for the development of local opera in the future. After investigation and analysis, it is known that the main problem of the current situation of the opera in the Poyang Lake area in northern Jiangxi is the construction of the troupe and the shrinking of the audience while innovation is the key point and the foothold to solve this problem.

At present, there are too few professional theater groups in the region, which are basically semi-professional performance groups and non-professional performance groups. The performances are also mainly based on entertainment, lacking artistry. There is no professional performance group, let alone effective management mechanism. Previously, a large number of rural young adults chose to go out for work, and township and urban audiences had the selectivity of multiple cultural consumption. Therefore, we are also faced with the problem of how to cultivate the audience.

Although the problems in the current situation of the operas in the Poyang Lake area in northern Jiangxi are related to many aspects, the root cause is still in the system. Therefore, how to deepen the reform of the cultural system and how to regulate the cultural market is a matter that requires serious consideration and solution to the change of the current situation of the opera in the region.

\section{REFERENCES}

[1] (Qing) Yu Tengqi. Binzhu Qinghua. Record of Wuning County [M]. Jiangxi People's Publishing House. 2009. (in Chinese)

[2] (Qing) Sheng Yue. Bi Cong. Record of Wuning County [M]. Jiangxi People's Publishing House. 2009. (in Chinese)

[3] (Qing) Yu Shao. "Poem of Bamboo pole in Changshuyuan". Record of Wuning County [M]. Jiangxi People's Publishing House. 2009. (in Chinese)

[4] Liu Zhiyuan. The Sichuan agriculture in the Han Dynasty in the archaeological materials. Cultural relics. 1979. (in Chinese)

[5] Su Shi. Dongpo Zhilin. Qingdao Publishing House. 2010. (in Chinese)

[6] Zhang Jingyuan. An attempt on exploring the origin of the Chushan drum from the county record. Wuning drumming song $[\mathrm{M}]$. Baihuazhou Literature and Art Press. 2009. (in Chinese) 